\title{
Partial Trisomy 1q21-qter and Partial Monosomy 7q21-qter Due to a Derivative Chromosome 7 in Myelodysplastic Syndrome Associated with Squamous Cell Carcinoma: Case Report
}

\author{
Abdulsamad Wafa1, Faten Moassass', Thomas Liehr², Abdulmunim Aljapawe3, \\ Walid Al Achkar ${ }^{*}$ \\ ${ }^{1}$ Chromosomes Laboratory, Human Genetics Division, Molecular Biology and Biotechnology Department, Syrian Atomic Energy \\ Commission, Damascus, Syria \\ ${ }^{2}$ Jena University Hospital, Institute of Human Genetics, Jena, Germany \\ ${ }^{3}$ Flow-Cytometry Unit, Mammalians Biology Division, Molecular Biology and Biotechnology Department, Syrian Atomic Energy \\ Commission, Damascus, Syria \\ Email: awafa@mail2world.com, fmoassass@mail2world.com, Thomas.Liehr@med.uni-jena.de, abdaljapawe@gmail.com, \\ *ascientific@aec.org.sy
}

How to cite this paper: Wafa, A., Moassass, F., Liehr, T., Aljapawe, A. and Al Achkar, W. (2016) Partial Trisomy 1q21-qter and Partial Monosomy 7q21-qter Due to a Derivative Chromosome 7 in Myelodysplastic Syndrome Associated with Squamous Cell Carcinoma: Case Report. Case Reports in Clinical Medicine, 5, 518-527.

http://dx.doi.org/10.4236/crcm.2016.512066

Received: October 27, 2016

Accepted: December 13, 2016

Published: December 16, 2016

Copyright $\odot 2016$ by authors and Scientific Research Publishing Inc. This work is licensed under the Creative Commons Attribution International License (CC BY 4.0).

http://creativecommons.org/licenses/by/4.0/

\section{Abstract}

Background: Myelodysplastic syndromes (MDS) are subtypes of hematological disorders which are known to have partial bone marrow dysplasia, peripheral cytopenia, and later on an increased risk to develop acute myeloid leukemia. Chromosomal aberrations are detected in $\sim 50 \%$ of cases of de novo MDS cases and the most common chromosomal abnormalities of this entity include complete or partial monosomy of chromosomes 5 and 7, partial deletion of $20 \mathrm{q}$ and $12 \mathrm{p}$, trisomy 8 , and 11q23 aberrations. A few primary and/or secondary MDS cases combined with other cancer have been reported. Case Presentation: We report here an adult MDS associated with squamous cell carcinoma (SCC). G-banding and array-proven multicolor banding (aMCB) revealed an unbalanced translocation $\operatorname{der}(7) t(1 ; 7)(q 21 ; q 21)$, which led to $1 \mathrm{q}$ partial trisomy and 7q partial monosomy. Immunophenotype of this case was consistent with refractory anemia with excess of blasts (RAEB-2) according to World Health Organization (WHO) classification. Conclusions: As far as we know, this is the first adult MDS case associated with SCC and an unbalanced translocation $t(1 ; 7)$. Our patient received first cycle of azacitidine treatment and he showed bilateral pleural effusion as a secondary event. This toxicity is 
not limited to the first cycle as in previous MDS cases; our case is the first one to shown this toxicity as a secondary event of azacitidine treatment. As less than 10 cytogenetcially comparable cases without SCC were reported before in male MDS, we carefully conclude that this cytogenetic aberration may be a hint on a new gender associated MDS subgroup.

\section{Keywords}

Myelodysplastic Syndrome (MDS), Cytogenetics, Fluorescence in Situ Hybridization (FISH), Squamous Cell Carcinoma (SCC), Prognostic Factors

\section{Introduction}

Myelodysplastic syndromes (MDS) belong to the hematological disorders. Characteristics for them are ineffective hematopoiesis, bone marrow dysplasia, peripheral cytopenia, and an increased risk to progress to an acute myeloid leukemia (AML). Epidemiology, surveillance, and clinical outcome of these acquired disorders support the view that MDS is an increasingly prevalent disease being predominant in advanced age (median age of 71 years). On the other hand MDS in childhood and young adult is reported. MDS has historically been categorized into two subtypes denominated as de novo or primary MDS and the secondary or therapy-related MDS (t-MDS) due to previous treatment regimens [1]. Chromosomal aberrations are detected in $\sim 50 \%$ of cases of de novo MDS; here t-MDS cases show the highest prevalence of cases with such acquired genetic changes, i.e. $90 \%$. The most common chromosomal abnormalities in MDS include monosomy of chromosomes 5 and/or 7, partial deletions of 5q, 7q, 20q and 12p, trisomy 8 and/or rearrangements including chromosomal subband 11q23 [2].

Oral squamous cell carcinoma (OSCC) is the entity being present in more than $90 \%$ of cases with SCC [3]. However, the etiology of OSCC is multifactorially-based and can be caused by tobacco, alcohol, syphilis, sunlight, radiation, phenol, viruses, malnutrition and/or iron deficiency anemia. Recent advances in OSCC research identified molecular-in parts diagnostically relevant-markers including oncogenes, tumor suppressor genes, cell proliferation markers, and intercellular adhesion molecules [4]. Yet only few primary and/or secondary MDS cases combined with other cancer are described in the literature [5]-[10].

Aberrations of chromosome 1 were identified to play a role in malignancies including MDS [4]. Trisomy or duplication of the long arm of chromosome 1 is the most frequent abnormality in MDS [6]. Literature survey on cytogenetic abnormalities involving chromosome 1 in myeloid neoplasms has highlighted chromosomal region 1q12-23 to be most often affected by gain of copy numbers [6].

Here, we report an MDS case associated with SCC that showed partial trisomy 1q21-qter together with a break in 7q21 due to a derivative chromosome 7 . The 
patient showed bilateral pleural effusion as a secondary event after first cycle of azacitidine treatment.

\section{Case Presentation}

A 28-year-old male, his social history was significant for 8 years smoking of cigarette (one pack per day), without familial medical history of cancer, presented with an 8 months history of moderately differentiated SCC in the left soft palate (for further details see Table 1). He was pale but lymph nodes were not enlarged. His past medical history was remarkable for polio virus infection, too.

Table 1. Clinical history of the patient together with diagnostic results and treatment.

Date Symptoms Analyses Treatment

24 Nov 2012 pancytopenia [Leucopenia (WBC 2.6

Moderately differentiated SCC in the left soft palate (ulceration and hard osteonecrosis of soft palate) + partial loss of vision in the left eye $\left.\times 10^{9} / 1\right)$, neutropenia $\left(1.2 \times 10^{9} / 1\right)$; anemia (Hgb $7.9 \mathrm{~g} / \mathrm{dl}$ ); thrombocytopenia (Plt $46 \times 10^{9} / 1$ ).

Peripheral blood (PB) showed

03 Dec 2013 pancytopenia (WBC $\left.2.6 \times 10^{9} / 1\right)$, neutropenia $\left(1.2 \times 10^{9} / 1\right)$; Hgb 7.9 g/dl); Plt $\left.46 \times 10^{9} / \mathrm{l}\right)$.

15 Dec 2013 Peripheral blood (PB) showed pancytopenia.

31 Dec 2013 Intolerance of Thalidomide drug.

He received several blood transfusions. PB showed

07 Jan 2014 pancytopenia (WBC $\left.1.6 \times 10^{9} / 1\right)$, neutropenia $\left(1.1 \times 10^{9} / \mathrm{l}\right)$; Hgb 6.7 g/dl); Plt $\left.92 \times 10^{9} / 1\right)$.
Vit(B12) $138 \mathrm{pg} / \mathrm{ml}$ (normal value 243 1100), and Vit(B9) 5.47 $\mathrm{ng} / \mathrm{ml}$ (normal 2.8 - 21).

- Bone marrow (BM) smear showed almost $20 \%$ of blats

Cytogenetic analyses and immunophenotyping were done at this point.
Thalidomide (50mg three times per day) for two weeks

Suggested Vidaza No Azacitidine treatment because the politi(Azacitidine) cal situation in his country.

He received Azacitidine $\left(75 \mathrm{mg} / \mathrm{m}^{2}\right)$ (first cycle in the first day)

Severe nausea, Syncope, Neuropathy.

He received blood transfusions.

He received several blood Transfusions. $\mathrm{PB}$ showed pancytopenia (WBC $1.8 \times 10^{9} / 1$ ), neutropenia $\left(1.1 \times 10^{9} / \mathrm{l}\right)$; $\left.\mathrm{Hgb} 7.4 \mathrm{~g} / \mathrm{dl}\right)$; Plt $\left.67 \times 10^{9} / 1\right)$.

Later he had bilateral pleural effusion, and
Stooped radiotherapy because the pancytopenia continues (WBC $1.9 \times 10^{9} / 1$ ), neutropenia $\left(1.1 \times 10^{9} / \mathrm{l}\right)$; Hgb $\left.10.6 \mathrm{~g} / \mathrm{dl}\right)$;

Plt $\left.39 \times 10^{9} / 1\right)$.

- Vit(B12) deficiency was treated but still suffered from pancytopenia.

- Banding cytogenetics revealed a karyotype 46,XY,der(7)t(1;7)(?;?)[11]/ 46,XY[9]

- Immunophenotyping result suggested RAEB-2 according to WHO classification.

- He received several blood Transfusions. heavy ascites. 
Banding cytogenetics after radiotherapy revealed a karyotype of 46,XY,der(7)t(1;7)(?;?)[11]/46,XY[9] (Figure 1). Further studies were performed based on molecular cytogenetics (Figure 2). Dual-color-Fluorescence in situ hybridization (D-FISH) using a specific whole painting probe (WCP) for chromosomes 1 and 7 showed an unbalanced translocation between chromosomes 1 and 7 (data not shown). Array-proven multicolor banding (aMCB), using probes for chromosomes 1 and 7 (Figure 2) indicated for the following final karyotype: 46,XY,der(7)t(1;7)(q21;q21)[11]/46,XY[9].

Immunophenotyping on bone marrow specimen characterized this case as refractory anemia with excess blasts (RAEB-2) according to WHO classification. Granulocytes and monocytes showed low side scatter profile. The CD $34^{+}$cell population represented $11 \%$ of gated cells. This population was positive for CD45 ${ }^{\mathrm{dim}}, \mathrm{CD} 33, \mathrm{MPO}$ and expressed CD13 and CD15 heterogeneously/dimly. This cell population was negative for HLA-DR, CD14 and lymphocytes markers.

\section{Discussion}

Here, we report the first MDS case associated with SCC in the literature. In bone marrow an unbalanced $\operatorname{der}(7) t(1 ; 7)(q 21 ; q 21)$ was found to be associated with MDS. In addition, our patient showed bilateral pleural effusion as a secondary event after received first cycle of azacitidine treatment. Complete or partial trisomy of the long arm of chromosome 1 (subbands (p10) and/or (q10)) is a recurrent anomaly of pediatric MDS both de novo and therapy-relatedmones. In

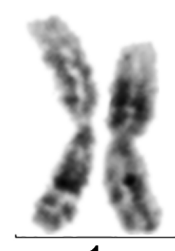

1

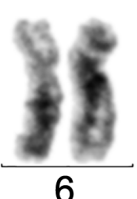

6

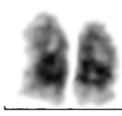

13

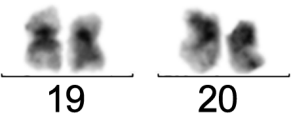

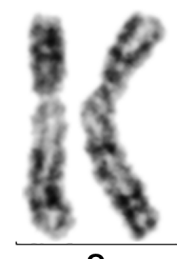

2
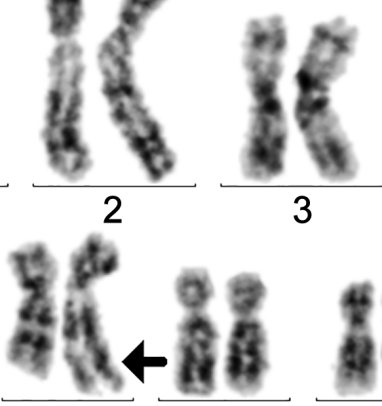

7

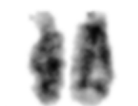

14

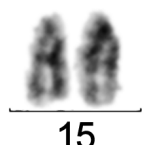

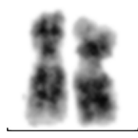
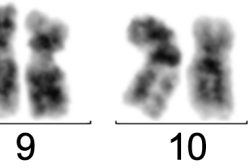

10

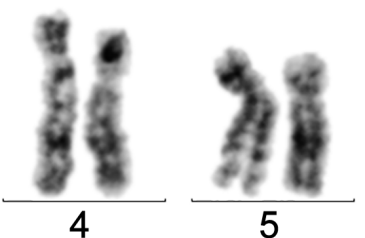

4

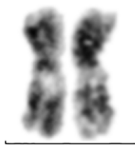

11

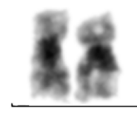

16
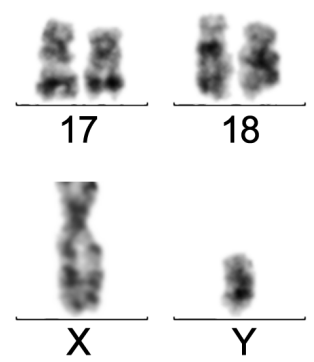

Figure 1. GTG-banding revealed the following karyotype: 46,XY,der(7)t(1;7)(q21;21). All derivative chromosomes are marked and highlighted by arrow heads. 

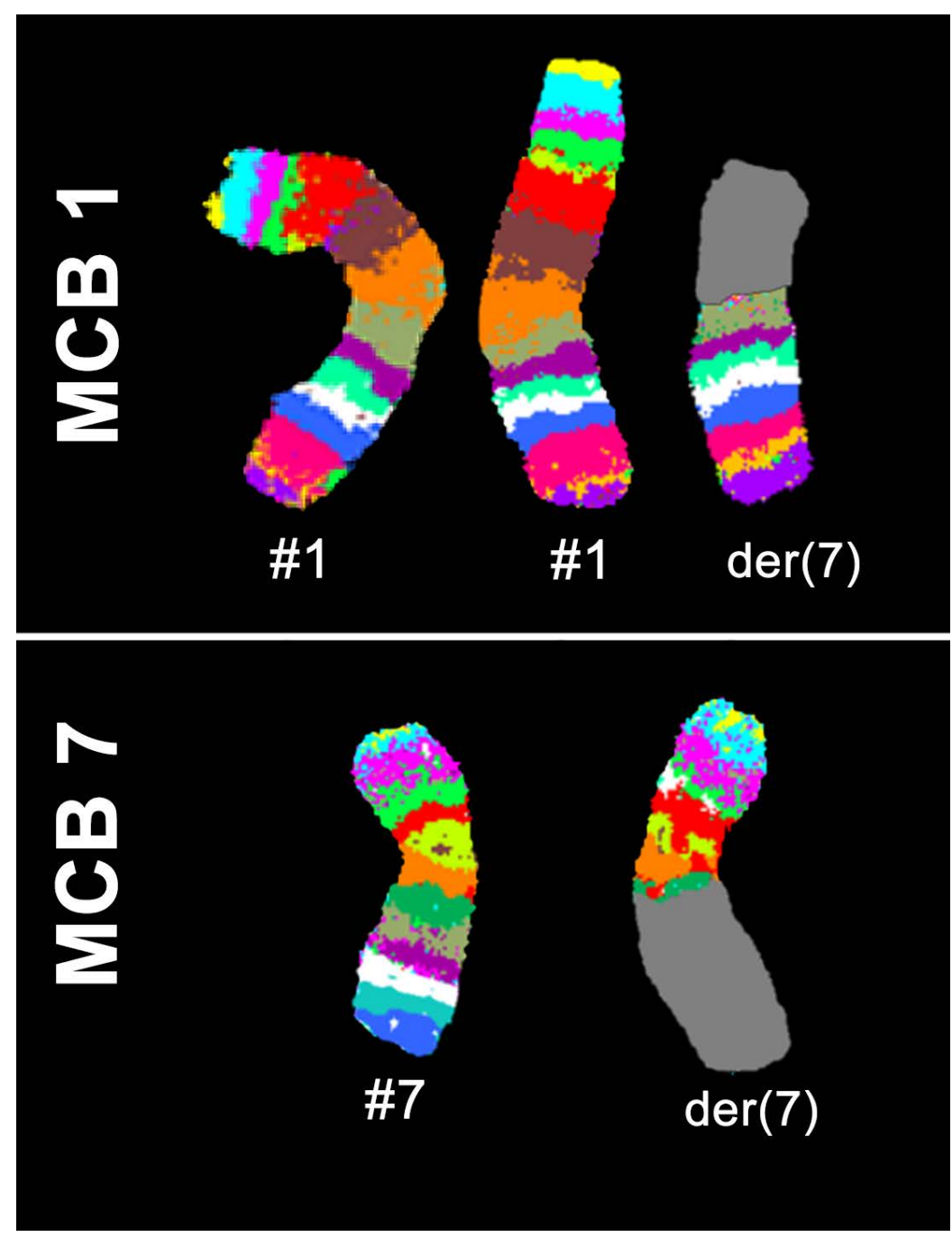

Figure 2. Array-proven multicolor banding (aMCB) results are shown. The normal chromosomes (\#) are depicted on the left side of each image and the derivative of the two chromosomes on the right side of normal chromosomes. The unstained regions when suing chromosome-specific aMCB-probe sets on the derivative chromosomes are shown in gray. Abbreviations: $\#$ = chromosome; der $=$ derivative chromosome.

majority of the cases this imbalance appears secondary to an unbalanced translocation where the more frequent partner is chromosome 7, involving subbands (p10) and/or (q10) [11]. However, unbalanced whole-arm translocations of 1q may involve different chromosomes [12]. Derivatives of these translocations have been shown to be dicentric in few cases such as $\operatorname{dic}(1 ; 7)$ and $\operatorname{dic}(1 ; 15)$ [9] [13]. Very few data are available about translocation $t(1 ; 7)$, which has been identified in 11 MDS cases involving short and/or long arms of the both chromosomes before, as reported in the Mitelman Database [12]. Among those MDS patients carrying a translocation $t(1 ; 7)$, two had MDS not otherwise specified, three a refractory anemia (RA), two had RA with ring sideroblasts, and four RA 
with excess blasts (RAEB) [12]. Notably, the majority of MDS patients showing translocation $\mathrm{t}(1 ; 7)$ described to date and including the present case report, were male, thus, although the number of reported cases is still limited, unbalanced translocation $t(1 ; 7)$ seems to preferentially associate with male sex [12]. In addition, the chromosomal bands $1 \mathrm{p} 21$ and $7 \mathrm{q} 21$ are involved in chromosomal rearrangements in 62 and 66 cases, respectively [12]. Moreover, Tassano et al. [10] described a two ( $\mathrm{t}-\mathrm{MDS}$ ) cases following chemo/radiotherapy for a primary solid tumor of neural crest origin, in the both cases the same subband 1q21 was involved. To the best of our knowledge, the present case report is the first one to observe an adult MDS case accompanied by SCC with unbalanced translocation $\mathrm{t}(1 ; 7)(\mathrm{q} 21 ; \mathrm{q} 21)$ leading to partial trisomy of 1q [12].

Aberrations of long arm of chromosome 1 (1q) are frequent among solid and hematological tumors. The most frequent partner chromosome to $1 \mathrm{q}$ are $7 \mathrm{q}$ in $\operatorname{der}(1 ; 7)$ and $16 \mathrm{p}$ in $\operatorname{der}(1 ; 16)$ leading to partial monosomies of the partner chromosomes [14]. A derivative chromosome 1 normally is observed as part of complex karyotypes and not like in our case as single aberration.

1q21.3 was recently found to be overrepresented in genomic instability of OSCC [6]. However, gains of chromosomal regions 1q21, 3q26.3, 5p15, 7p12, $8 \mathrm{q} 24,9 \mathrm{q} 34,11 \mathrm{q} 13$ and $20 \mathrm{q} 12$, as well as deletions of 3p, 4q, 5q, 7q22, 8p23, 9p21, $13 q 12-24,17 p, 18 q 21,21 q 11-21$ and 22q were previously observed in head and neck SCC by CGH studies [15]. In 1q21.3-q22 potential oncogenes such as $H A X-1, M U C 1$ and $C K S 1 B$ genes are localized. Amplification and overexpression of these potential oncogenes has previously been reported also in OSCC [16] [17].

$10 \%-30 \%$ of AML cases and approximately $27 \%$ of MDS cases were therapy-related myeloid neoplasms ( $\mathrm{t}-\mathrm{MN}$ ), which has been recognized already since the 1970s. Cytogenetic findings pointing towards high-risk diseases involve loss of chromosomes 5 and/or 7; poor prognosis in t-MNs compared to the corresponding primary diseases can be found for such aberrations. Median survival was 8 months in t-MNs compared to 5 -year survival of $10 \%$ in the other cases [18]. This adverse outcome seems to be connected with high-risk karyotypes in myeloid neoplasms treated by chemotherapy. On the other side, the incidence of high-risk karyotypes in MDS and AML treated by radiation therapy is similar to that observed in de novo disease. Furthermore, the clinical behavior of post radiation therapy of MDS is affected by bone marrow blast count. Overall this suggests that the clinical management of patients who develop MDS or AML applying radiation therapy should be administered only to de novo and not to therapy-related diseases [18].

RAEB-2 subtype of MDS accounts for $50 \%$ - 75\% of MDS cases. Aberrations like del $(5 q),-7,+8,-17 p$, del $(11 q 23)$, translocation $t(11 ; N)(q 23 ; N),-13$, del(13q) are the commonly observed in RAEB-2 [19]. High risk group includes chromosome 7 anomalies and complex karyotypes (with three or more aberra- 
tions) [20]; the median survival of this group was 0.2 year only, and the rate for developing an AML was 0.4 year according to the MDS IPSS classifies [19].

The long arm of chromosome 7, especially $7 \mathrm{q} 22$ to $7 \mathrm{q} 36$ harbors one or more tumor suppressor genes related to AML [21]. In contrast, 7q22 could be a critical region in the pathogenesis of MDS/AML; candidate genes of this region could be $E P O, T R F 2, E P H B 4$ or CLDN15 [22].

Azacitidine is a pyrimidine nucleoside analog that is used routinely in MDS treatment. Its mechanism of action involves hypomethylation of DNA, that results in increased expression of multiple genes and leads to enhanced cellular maturation [23]. However, azacitidine has been associated with various adverse reactions including nausea, pyrexia, diarrhea, fatigue, cough, dyspnea, and bone marrow suppression, which might result in febrile neutropenia, bleeding, and anemia. Moreover, induced interstitial lung disease (ILD) is probably a rare adverse reaction secondary to azacitidine [24].

According to the literature, five previously reported cases of ILD in association with hypomethylating agents for treatment of MDS: four were reported in connection with azacitidine [25] [26] [27] [28] and one with decitabine [29]. Also, Alnimer et al. [24] recently reported an MDS case treated with two cycles of azacitidine and his patient developed pneumonia secondary to azacitidine treatment. Our patient showed ILD (bilateral pleural effusion) as a secondary event after the first cycle of azacitidine treatment. This toxicity was not limited to the first cycle as in previous cases [24]-[29]; furthermore, pleural effusion could be associated with this toxicity.

\section{Conclusion}

In conclusion, we describe here an adult MDS case associated with SCC with partial trisomy of $1 \mathrm{q}$, partial monosomy $7 \mathrm{q}$ as sole clonal abnormalities, and the patient revealed bilateral pleural effusion as a secondary event after receiving the first cycle of azacitidine treatment. Prognostic significance of $\operatorname{der}(7) t(1 ; 7)$ still remains to be determined; however, most likely it is adverse and associated preferentially found in male MDS patients.

\section{Acknowledgements}

We thank Prof. I. Othman, the Director General of Syrian Atomic Energy Commission (SAEC) and Dr. N. Mirali, Head of Molecular Biology and Biotechnology Dept. for their support. This work was supported by the AECS.

\section{Competing Interests}

The author(s) declare that they have no competing interests.

\section{Authors' Contributions}

AW and FM examined the case and/or did initial cytogenetic analysis and FISH- 
tests; AA did the flow-cytometry analysis; TL did detailed FISH studies. WA supervised the cytogenetic analysis as chef of the cytogenetic laboratory. AW and TL drafted the paper and all authors read and approved the final manuscript.

\section{References}

[1] Arber, D.A., Orazi, A., Hasserjian, R., Thiele, J., Borowitz, M.J., Le Beau, M.M., Bloomfield, C.D., Cazzola, M. and Vardiman, J.W. (2016) The 2016 Revision of the World Health Organization (WHO) Classification of Lymphoid Neoplasms. Blood, 127, 2391-2405. https://doi.org/10.1182/blood-2016-03-643544

[2] Fenaux, P., Morel, P. and Lai, J.L. (1996) Cytogenetics of Myelodysplastic Syndroms. Seminars in Hematology, 33, 127-138.

[3] Jemal, A., Bray, F., Center, M.M., Ferlay, J., Ward, E. and Forman, D. (2011) Global Cancer Statistics. CA: A Cancer Journal for Clinicians, 61, 69-90. https://doi.org/10.3322/caac.20107

[4] Warnakulasuriya, S. (2009) Global Epidemiology of Oral and Oropharyngeal Cancer. Oral Oncology, 45, 309-316. https://doi.org/10.1016/j.oraloncology.2008.06.002

[5] Kondo, H. and Shinbo, I. (1997) Myelodysplastic Syndrome Associated with Gastric Cancer and Colon Polyp. Rinsho Ketsueki, 38, 1234-1237.

[6] Baccon, P.L., Leroux, D., Dascalescu, C., Duley, S., Marais, D., Esmenjaud, E., Sotto, J.J. and Callanan, M. (2001) Novel Evidence of a Role for Chromosome 1 Pericentric Heterochromatin in the Pathogenesis of B-Cell Lymphoma and Multiple Myeloma. Genes Chromosomes Cancer, 32, 250-264. https://doi.org/10.1002/gcc.1189

[7] Takahashi, T., Kazama, Y., Shimizu, H., Yoshimoto, M., Tsujisaki, M., Aoki, S. and Imai, K. (2001) Myelodysplastic Syndrome Progresses Rapidly into Erythroleukemia Associated with Synchronous Double Cancers of the Stomach and the Papilla of Vater. International Journal of Hematology, 74, 64-69. https://doi.org/10.1007/BF02982551

[8] Meng, D., Chai, Y.L., He, Y.F., Hu, H., Liu, R. and Liu, Z. (2014) Cervical Carcinoma Following Myelodysplastic Syndrome: A Case Report. Oncology Letters, 8, 8284.

[9] Wang, Y.H., Fu, R. and Shao, Z.H. (2013) An Exceptional Case of Myelodysplastic Syndrome with Myelofibrosis Following Combination Chemotherapy for Squamous Cell Lung Cancer. Cancer Biology \& Medicine, 10, 117-120.

[10] Tassano, E., Tavella, E., Valli, R., Micalizzi, C., Cuoco, C., Maserati, E., Pasquali, F. and Morerio, C. (2012) New Recurrent Chromosome Change in Pediatric TherapyRelated Myelodysplastic Syndrome: Unbalanced Translocation 1/6 with Cryptic Duplication of Short Arm of Chromosome 6. Leukemia \& Lymphoma, 53, 24342438. https://doi.org/10.3109/10428194.2012.695778

[11] Morerio, C., et al. (2006) Gain of 1q in Pediatric Myelodysplastic Syndromes. Leukemia Research, 30, 1437-1441. https://doi.org/10.1016/j.leukres.2005.12.022

[12] Mitelman, F., Johansson, B. and Mertens, F. (2015) Mitelman Database of Chromosome Aberrations and Gene Fusions in Cancer. http://cgap.nci.nih.gov/Chromosomes/Mitelman

[13] Alitalo, T., Willard, H.F. and de la Chapelle, A. (1989) Determination of the Breakpoints of 1;7 Translocations in Myelodysplastic Syndrome by in Situ Hybridization Using Chromosome-Specific Alpha Satellite DNA from Human Chromosomes 1 and 7. Cytogenetics and Cell Genetics, 50, 49-53. https://doi.org/10.1159/000132718 
[14] Fogu, G., et al. (2012) Unbalanced 1q Whole-Arm Translocation Resulting in $\operatorname{Der}(14) \mathrm{t}(1 ; 14)(\mathrm{q} 11-12 ; \mathrm{p} 11)$ in Myelodysplastic Syndrome. Cytogenetic and Genome Research, 136, 256-263. https://doi.org/10.1159/000338437

[15] Singh, B., et al. (2001) Molecular Cytogenetic Characterization of Head and Neck Squamous Cell Carcinoma and Refinement of 3q Amplification. Cancer Research, 61, 4506-4513.

[16] Ramsay, A.G., et al. (2007) HS1-Associated Protein X-1 Regulates Carcinoma Cell Migration and Invasion via Clathrin-Mediated Endocytosis of Integrin $\alpha_{v} \beta_{6}$. Cancer Research, 67, 5275-5284. https://doi.org/10.1158/0008-5472.CAN-07-0318

[17] Martín-Ezquerra, G., et al. (2011) CDC28 Protein Kinase Regulatory Subunit 1B (CKS1B) Expression and Genetic Status Analysis in Oral Squamous Cell Carcinoma. Histology and Histopathology, 26, 71-77.

[18] Nardi, V., et al. (2012) Acute Myeloid Leukemia and Myelodysplastic Syndromes after Radiation Therapy Are Similar to De Novo Disease and Differ from Other Therapy-Related Myeloid Neoplasms. Journal of Clinical Oncology, 30, 2340-2347. https://doi.org/10.1200/JCO.2011.38.7340

[19] Malcovati, L. and Nimer, S.D. (2008) Myelodysplastic Syndromes: Diagnosis and Staging. Cancer Control, 15, 4-13.

[20] Malcovati, L., et al. (2007) Time-Dependent Prognostic Scoring System for Predicting Survival and Leukemic Evolution in Myelodysplastic Syndromes. Journal of Clinical Oncology, 25, 3503-3510. https://doi.org/10.1200/JCO.2006.08.5696

[21] Chen, Z., Pasquini, M., Hong, B., Dehart, S., Heikens, M. and Tsai, S. (2005) The Human Penumbra Gene Is Mapped to a Region on Chromosome 7 Frequently Deleted in Myeloid Malignancies. Cancer Genetics and Cytogenetics, 162, 95-98. https://doi.org/10.1016/j.cancergencyto.2005.03.017

[22] Thiel, A., et al. (2011) Comprehensive Array CGH of Normal Karyotype Myelodysplastic Syndromes Reveals Hidden Recurrent and Individual Genomic Copy Number Alterations with Prognostic Relevance. Leukemia, 25, 387-399. https://doi.org/10.1038/leu.2010.293

[23] Bouchard, J. (1989) Mechanism of Action of 5-AZA-dC: Induced DNA Hypomethylation Does Not Lead to Aberrant Gene Expression in Human Leukemic CEM Cells. Leukemia Research, 13, 715-722. https://doi.org/10.1016/0145-2126(89)90061-1

[24] Alnimer, Y., Salah, S., Abuqayas, B. and Alrabi, K. (2016) Azacitidine-Induced Cryptogenic Organizing Pneumonia: A Case Report and Review of the Literature. Journal of Medical Case Reports, 10, 15. https://doi.org/10.1186/s13256-016-0803-0

[25] Adams, C.D., Szumita, P.M., Baroletti, S.A. and Lilly, C.M. (2005) Azacitidine-Induced Interstitial and Alveolar Fibrosis in a Patient with Myelodysplastic Syndrome. Pharmacotherapy, 25, 765-768. https://doi.org/10.1592/phco.25.5.765.63579

[26] Sekhri, A., Palaniswamy, C., Kurmayagari, K., Kalra, A. and Selvaraj, D.R. (2012) Interstitial Lung Disease Associated with Azacitidine Use: A Case Report. American Journal of Therapeutics, 19, e98-e100. https://doi.org/10.1097/MJT.0b013e3181e7a526

[27] Kuroda, J., Shimura, Y., Mizutani, S., Nagoshi, H., Kiyota, M., Chinen, Y., et al. (2014) Azacitidine-Associated Acute Interstitial Pneumonitis. Internal Medicine ( Tokyo, Japan), 53, 1165-1169. 
[28] Hueser, C.N. and Patel, A.J. (2007) Azacitidine-Associated Hyperthermia and Interstitial Pneumonitis in a Patient with Myelodysplastic Syndrome. Pharmacotherapy, 27, 1759-1762. https://doi.org/10.1592/phco.27.12.1759

[29] Vasu, T.S., Cavallazzi, R., Hirani, A. and Marik, P.E. (2009) A 64-Year-Old Male with Fever and Persistent Lung Infiltrate. Respiratory Care, 54, 1263-1265.

\section{List of Abbreviations}

Myelodysplastic syndrome (MDS), acute myeloid leukemia (AML), therapyrelated (t-MDS), squamous cell carcinoma (SCC), array-proven multicolor banding (aMCB), refractory anemia with excess blasts (RAEB-2), World Health Organization (WHO), tumor suppressor genes (TSGs), oral squamous cell carcinoma (OSCC), Fluorescence in situ hybridization (FISH), whole chromosome painting (WCP) probes, DAPI (4',6-diamino-2-phenylindole), Dual-color-FISH (D-FISH), refractory anemia (RA), International Prognostic Scoring System (IPSS).

Submit or recommend next manuscript to SCIRP and we will provide best service for you:

Accepting pre-submission inquiries through Email, Facebook, LinkedIn, Twitter, etc.

A wide selection of journals (inclusive of 9 subjects, more than 200 journals)

Providing 24-hour high-quality service

User-friendly online submission system

Fair and swift peer-review system

Efficient typesetting and proofreading procedure

Display of the result of downloads and visits, as well as the number of cited articles

Maximum dissemination of your research work

Submit your manuscript at: http://papersubmission.scirp.org/

Or contact crcm@scirp.org 